\title{
Applications of graphene-based materials in environmental protection and detection
}

\author{
LÜ MeiJiao, LI Jing, YANG XuYu, ZHANG ChangAn, YANG Jia, HU Hao \& \\ WANG XianBao*
}

Key Laboratory for the Green Preparation and Application of Functional Materials Ministry of Education; Faculty of Materials Science and Engineering, Hubei University, Wuhan 430062, China

Received January 25, 2013; accepted March 27, 2013; published online June 18, 2013

\begin{abstract}
Many efficient adsorbents and sensors based on graphene and functionalized graphene have been constructed for the removal and detection of environmental pollutants due to its unique physicochemical properties. In this article, recent research achievements are reviewed on the application of graphene-based materials in the environmental protection and detection. For environmental protection, modified graphene can adsorb heavy metal ions in a high efficiency and selectivity, and thus reduces them to metals for recycling. High adsorption capacity of graphene-based materials to kinds of organic pollutants in water was also presented. Several graphene-based sensors with high limit of detection were reported to detect heavy metal ions, toxic gases and organic pollutants in environment. Finally, a perspective on the future challenge of adsorbents and detection devices based on graphene is given.
\end{abstract}

graphene, environmental protection and detection, adsorbent, sensor

Citation: $\quad$ Lü M J, Li J, Yang X Y, et al. Applications of graphene-based materials in environmental protection and detection. Chin Sci Bull, 2013, 58: 2698-2710, doi: 10.1007/s11434-013-5887-y

Environmental pollution especially toxic gases, heavy metal ions and organic pollutants in air and water, caused by industry and agricultural activities, severely threaten ecological balance and human health, and have received extensive attention worldwide. For example, the heavy metal ions in bodies accumulated from the food chains will cause various chronic diseases. Therefore, it is necessary to develop simple, sensitive and inexpensive methods to remove and detect these pollutants. Currently, many efficient adsorbents and sensitive detection devices based on nanomaterials especially graphene have been designed due to their unique chemical, thermal, electronic, and mechanical properties.

Graphene, a two-dimensional (2D) one atom thick nanomaterial consisting of $\mathrm{sp}^{2}$-hybridized carbon, has attracted great interest among scientists due to its unique properties, including high specific surface area (SSA) of $2600 \mathrm{~m}^{2} \mathrm{~g}^{-1}$ [1], excellent thermal conductivities of $5000 \mathrm{~W} \mathrm{~m}^{-1} \mathrm{~K}^{-1}$ [2],

*Corresponding author (email: wangxb68@aliyun.com) high-speed electron mobility of $200000 \mathrm{~cm}^{2} \mathrm{~V}^{-1} \mathrm{~s}^{-1}$ at room temperature [3], high stiffness and strength with Young's modulus of around $1000 \mathrm{GPa}$ and break strength of $130 \mathrm{GPa}$ [4], extraordinary electrocatalytic activity [5] and optical properties [6]. These outstanding physicochemical properties indicate its potential application in many research fields. For example, considering the high surface area and strong adsorption capacity of graphene, many efficient adsorbents [7] and photocatalysts [8] are developed for the removal and photocatalytic degradation of pollutants. Moreover, based on the excellent electrical conductivity and optical properties of graphene, many sensitive electrochemical [9] and fluorescent [10] sensors are also designed for the detection of pollutants. However, aggregations of graphene decrease its available surface area and further reduce its adsorption capacity. Functionalization of graphene with molecules, which have water-solubility and affinity toward target analytes, will improve the selectivity of adsorbents or detection devices, as well as prevent the aggregation. Based on this 
idea, diverse derivatives of graphene have been reported and applied to environmental protection and detection.

Herein, we review recent research achievements based on graphene and its derivatives for environmental protection and detection. Meanwhile, according to the categories of environment pollutants, such as toxic gases, heavy metal ions and organic pollutants, we describe several selected examples to introduce the application of graphene in the removal and detection of these pollutants.

\section{Functionalized graphene for environmental protection}

\subsection{Adsorption and reduction for heavy metal ions}

Heavy metal ions, such as lead $\left(\mathrm{Pb}^{2+}\right)$, cadmium $\left(\mathrm{Cd}^{2+}\right)$, chromium $\left(\mathrm{Cr}^{3+}, \mathrm{Cr}^{6+}\right)$, mercury $\left(\mathrm{Hg}^{2+}\right)$, copper $\left(\mathrm{Cu}^{2+}\right)$ and arsenic $\left(\mathrm{As}^{3+}\right)$, have severe risks to environment and human health, and need to be removed from soil and water. Graphene and its derivatives with high surface areas and many functional groups, which benefit to the adsorption or preconcentration of heavy metal ions, are given great attention in the present researches.

Graphene oxide (GO) and reduced graphene oxide (RGO) with many functional groups such as $-\mathrm{O}-,-\mathrm{OH}$, and
- $\mathrm{COOH}$, which can form complexes with metal ions, are used to remove heavy metal ions. Zheng et al. [11] reported low-temperature exfoliated graphene nanosheets (GNS), which could be used to adsorb $\mathrm{Pb}^{2+}$ from aqueous system. The morphology and SSA did not show apparent differences although the adsorption capacity against $\mathrm{Pb}^{2+}$ is enhanced obviously after heat treatment, and the enhanced adsorption capacity was ascribed to the increase in the Lewis basicity and electrostatic attraction of graphene. Recently, RGO obtained by a modified Hummers method has an adsorption capacity of $8.06 \times 10^{-3} \mathrm{~g} \mathrm{~g}^{-1}$ for antimony (III) $\mathrm{Sb}^{3+}$ [12]. In order to overcome the hydrophobicity of graphene, which limits the capacity of removing heavy metal ions in wastewater to some extent, a stable and water-dispersible GNS was prepared by a one-step route [13]. In that method, Tea polyphenols was used as a simultaneous reductant and functionalization reagent, and the obtained tea polyphenols-graphene showed superior adsorption efficiency and selectivity for $\mathrm{Pb}^{2+}$ in aqueous solution. Compared with graphene, GO with more oxygen-containing groups display a higher adsorption capacity. Mi et al. [14] prepared a GO aerogel with highly oriented porous structure from GO nanosheets by a unidirectional freeze-drying method. The obtained aerogel can act as a good adsorbent of $\mathrm{Cu}^{2+}$ in aqueous solutions with fast adsorption rate, which attributed

(a)
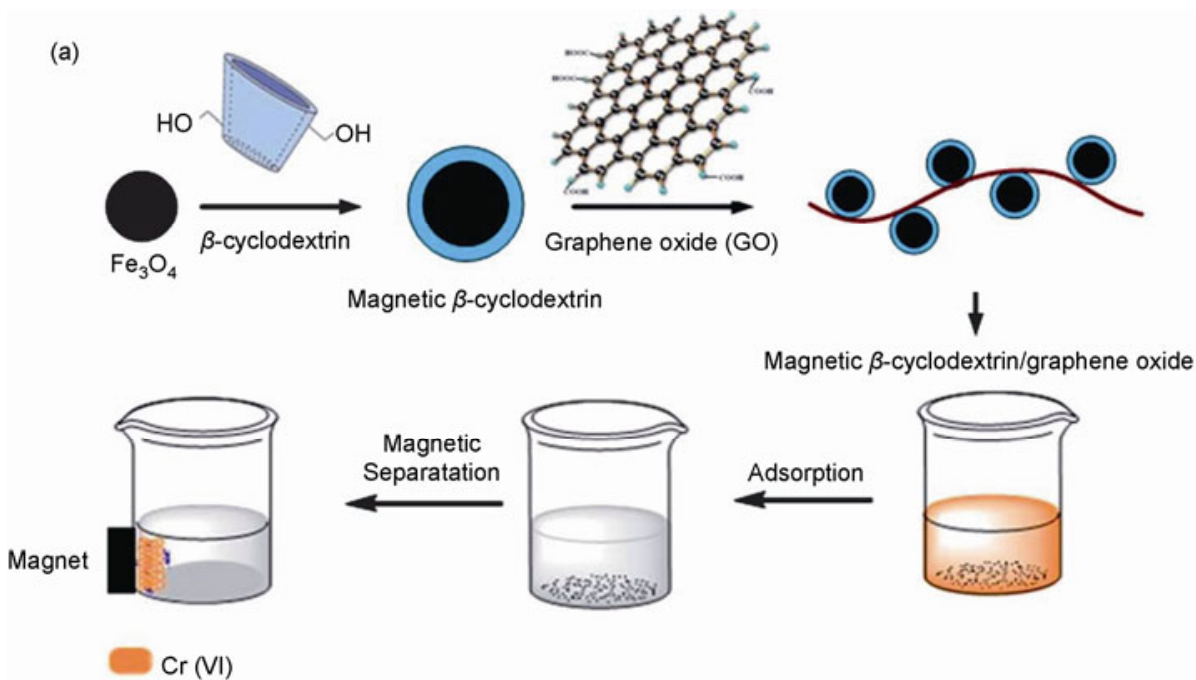

(b)
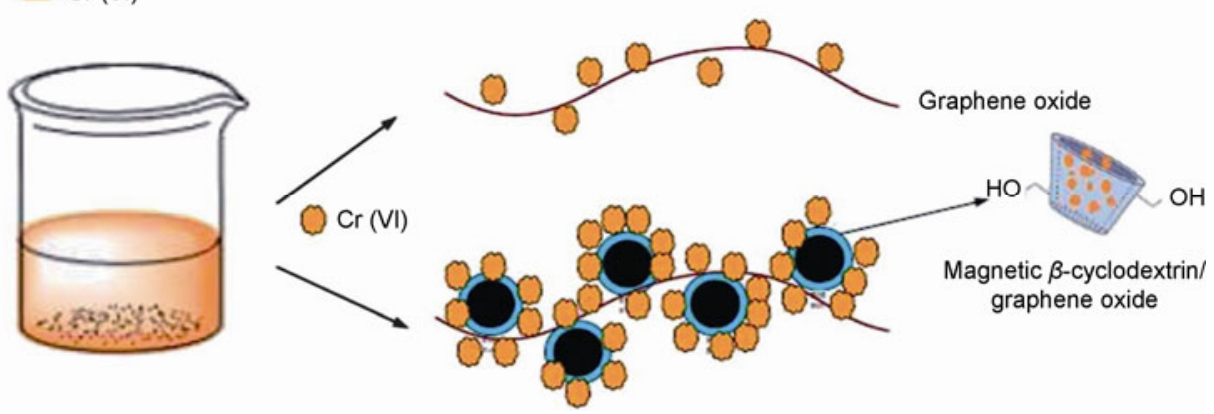

Figure 1 (Color online) (a) The synthesis and application for removing $\mathrm{Cr}^{6+}$ of MCGNs. (b) the comparison of adsorption mechanisms on GO and MCGN. Reprinted from ref. [25] with permission from the Royal Society of Chemistry. 
to its interconnected pore structure being conducive to the diffusion of $\mathrm{Cu}^{2+}$. According to Zhao's group [15], fewlayered GO nanosheets had also a higher adsorption capacity for $\mathrm{Cd}^{2+}\left(0.106 \mathrm{~g} \mathrm{~g}^{-1}\right)$ and $\mathrm{Co}^{2+}\left(0.068 \mathrm{~g} \mathrm{~g}^{-1}\right)$, and it also can be an adsorbent of Uranium (VI) $\left(0.299 \mathrm{~g} \mathrm{~g}^{-1}\right)$ [16].

Graphene functionalized with metal oxides, such as $\mathrm{Fe}_{3} \mathrm{O}_{4}$ [17,18], $\mathrm{MnO}_{2}[19,20], \mathrm{Al}_{2} \mathrm{O}_{3}$ [21], $\mathrm{TiO}_{2}$ [22], $\mathrm{ZnO}$ $[23,24]$, has also attracted great interest in scientists for the reduction and removal of heavy metal ions. Among these metal oxides, Iron-oxides especially $\mathrm{Fe}_{3} \mathrm{O}_{4}$ nanoparticles have been investigated widely due to the magnetism in favor of separation. Fan et al. [25] fabricated a magnetic $\beta$-cyclodextrin/GO nanocomposite (MCGN) with a large saturation magnetization of $50.13 \mathrm{emu} \mathrm{g}^{-1}$ by the amidation of the carboxyl group of $\mathrm{GO}$ with the amine group of magnetic $\mathrm{NH}_{2}-\beta$-cyclodextrin, which combined the unique properties of magnetic cyclodextrin (e.g. super-paramagnetism, high adsorption capability and strong acidresistance) and GO (e.g. large surface area and good mechanical properties). This MCGN displayed fast removal of $\mathrm{Cr}(\mathrm{VI})$ in wastewater with a high adsorption capability of $0.12 \mathrm{~g} \mathrm{~g}^{-1}$, and can be reused by treating the $\mathrm{Cr}$ (VI)adsorbed MCGN with $\mathrm{NaOH}$ solution. The synthesis and application for the removal and adsorption mechanism of $\mathrm{Cr}$ (VI) are shown in Figure 1(a) and (b). In their later experiment, they synthesized water-dispersible magnetic chitosan/GO composites with the similar method [26], and it can be used as a sorbent of $\mathrm{Pb}$ (II) with a maximum adsorption capacity of $0.077 \mathrm{~g} \mathrm{~g}^{-1}$ from large volumes of aqueous solutions. For comparison, a method of simultaneous removal of $\mathrm{Cr}$ (VI) and $\mathrm{Pb}$ (II) with higher adsorption capacities was reported by Cong et al. [27]. They investigated a facile one-step synthesis of three-dimensional (3D) macroscopic graphene/iron oxide hydrogels. The formation mechanism was based on the synergistic effect of the selfassembly of GO sheets and in situ simultaneous deposition of metal oxide nanoparticles, such as $\alpha-\mathrm{FeOOH}$ nanorods and magnetic $\mathrm{Fe}_{3} \mathrm{O}_{4}$ nanoparticles on GNS, which were produced by reduction of ferrous under mild conditions (Figure 2(a)). The adsorption behavior of graphene/ $\alpha$ $\mathrm{FeOOH}$ hydrogel for $\mathrm{Cr}$ (VI) or $\mathrm{Pb}$ (II) was investigated (Figure 2(b)), and the maximum adsorption capacities for
$\mathrm{Cr}(\mathrm{VI})$ and $\mathrm{Pb}$ (II) were 0.139 and $0.374 \mathrm{~g} \mathrm{~g}^{-1}$, respectively, which indicated it could be an ideal adsorbent in industrial water purification. More importantly, other 3D macroscopic graphene/metal oxide hydrogels such as graphene $/ \mathrm{Mn}_{2} \mathrm{O}_{3}$, graphene/ $\mathrm{CeO}_{2}$ could be synthesized in the same way. For the removal of As (III) and As (V), Chandra et al. [28] synthesized water-dispersible magnetite-RGO hybrids via chemical precipitation of $\mathrm{Fe}^{3+}$ and $\mathrm{Fe}^{2+}$ in the solution of GO, and it showed near completely (over 99.9\%) removal of As within $1 \times 10^{-6} \mathrm{~g} \mathrm{~L}^{-1}$. Compared with it, Bhunia et al. [29] prepared a porous iron-iron oxide matrix dispersed on RGO, which had a higher surface area and adsorption capacity for As (III) $\left(0.044 \mathrm{~g} \mathrm{~g}^{-1}\right)$.

Photocatalytic degradation, as an effective method, is also applied to the removal of heavy metal ions widely, especially for $\mathrm{Cr}$ (VI). Traditional photocatalysts such as $\mathrm{TiO}_{2}$ and $\mathrm{ZnO}$ combined with graphene possess a higher catalytic activity for degradation of $\mathrm{Cr}^{6+}$ than pure $\mathrm{TiO}_{2}$ and $\mathrm{ZnO}$. Jiang et al. [30] synthesized two-dimensional (2D) porous graphene/ $/ \mathrm{TiO}_{2}$ composites by in situ depositing $\mathrm{TiO}_{2}$ nanoparticles on GO and calcining at $200^{\circ} \mathrm{C}$. The obtained $\mathrm{TiO}_{2}$-RGO exhibited 5.4 times higher photo-reductive conversion rate than that of $\mathrm{P} 25$ for $\mathrm{Cr}$ (VI). Meanwhile, $\mathrm{ZnO}$ RGO had a maximum removal rate of $96 \%$ under UV light irradiation for $\mathrm{Cr}(\mathrm{VI})$ compared with pure $\mathrm{ZnO}(67 \%)$ [23].

In addition, graphene modified with some polymer and organic molecules demonstrates good adsorption to heavy metal ions. For example, polypyrrole-RGO composite can adsorb $\mathrm{Hg}^{2+}$ selectively, with the adsorption capacity of $0.98 \mathrm{~g} \mathrm{~g}^{-1}$ [31]. Ethylene diamine tetraacetic acid-GO can remove $\mathrm{Pb}^{2+}$ with an adsorption capacity of $0.479 \mathrm{~g} \mathrm{~g}^{-1}$ [32]. $\mathrm{Cr}$ (VI) can be also reduced and removed by ethylenediamine-RGO [33].

\subsection{Adsorption for organic pollutants}

Organic pollutants in wastewater, especially for oils and organic solvents, dyes, phenolic comopunds and pesticides, need to be removed timely because of their severe risks. At present, many methods based on graphene have been presented and will be applied to environmental protection gradually.
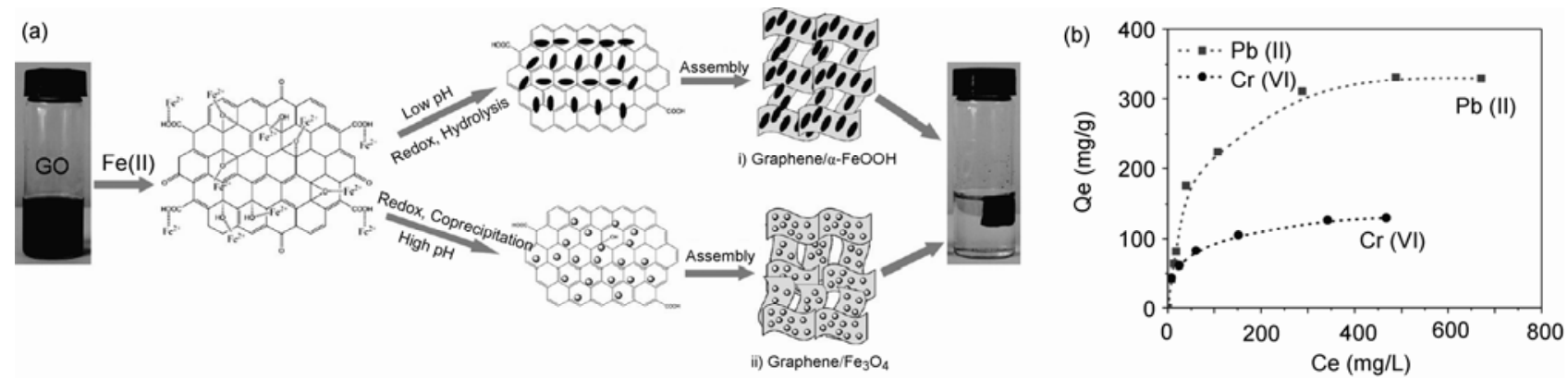

Figure 2 (a) The formation mechanism of graphene/iron oxide hydrogel; (b) the adsorption isotherms of $\mathrm{Cr}^{6+}$ and $\mathrm{Pb}^{2+}$ on graphene/FeOOH hydrogel at room temperature. Reprinted from ref. [27] with permission from the American chemical Society. 
Compared with 2D graphene sheets, 3D graphene sponges or foams have attracted extensive attention due to the high porosity for the practical application of being a high-efficient adsorbent. For example, Sun et al. [34] made ultra-flyweight and multifunctional carbon aerogels by freeze-drying aqueous solution of CNTs and giant graphene oxide sheets, it could be obtained for the desired densities and shapes such as rods, cylinder, and papers (Figure 3(a) and (b)). More importantly, it exhibited super-high adsorption capacity and ultra-fast adsorption rate for oil and organic solvents. Wang et al. [35] fabricated a 3D architectures of graphene, based on the chemical reduction of GO with the assist of natural phenolic acids (gallic acid GA) and in situ self-assembly of graphene sheets through $\pi-\pi$ interactions. The obtained 3D graphene exhibited super hydrophobicity, low density (10000-20000 $\mathrm{g} \mathrm{m}^{-3}$ ) and high porosity (SSA $100-350 \mathrm{~m}^{2}$ ), and was proved to have excellent adsortion capacity and fast adsorption rate towards oils and organic solvents. Their morphology and capacity of adsorption are displayed in Figure 3(c), (d) and (e). Similarly, Zhao et al. [36] prepared spongy graphene (SG) by self-assembly of GO sheets under the assistance of thiourea. This SG had a tunable pore structure, and displayed high adsorption capacity of $129 \mathrm{~g} \mathrm{~g}^{-1}$ to diesel oil, which was mainly related to its SSA of $399 \mathrm{~m}^{2} \mathrm{~g}^{-1}$. Compared with it, a shapemouldable SG with a higher SSA of $423 \mathrm{~m}^{2} \mathrm{~g}^{-1}$ was developed by $\mathrm{Bi}$ and co-workers [37]. The acquired SG exhibited highly efficient absorption towards toxic solvents as well as petroleum products and fats, even up to 86 times of its weight. More importantly, it can be reused more than 10 times after removing the adsorbates via heat treatment. It is well known the hydrophobicity can be improved by surface roughness. Based on this idea, superhydrophobic and superoleophilic 3D graphene-carbon nanotubes hybrids were synthesised by Dong's group [38]. It can be employed to remove oils and organic solvents selectively from the surface of water with high adsorption capacity and well recyclability.

Dyes from industries are the major source of water pollution, and many adsorbents based on graphene are reported to removal the pollutants in recent years. For instance, Liu et al. [39] reported that graphene prepared by a modified Hummers' method had the maximum adsorption capacity of $0.153 \mathrm{~g} \mathrm{~g}^{-1}$ to methylene blue. Zhang et al. [40] presented polyethersulfone enwrapped GO, which showed porous structures inside and a dense skin layer, and displayed well-selective adsorbability to cationic dyes such as methylene blue and methyl violet. In order to extract the adsorbents from solution easily and rapidly after adsorbing dyes, $\mathrm{Fe}_{3} \mathrm{O}_{4}$ is used widely due to its strong superparamagnetism in favor of separation. So far, many composites based on graphene and $\mathrm{Fe}_{3} \mathrm{O}_{4}$ have been synthesized such as GO- $\mathrm{Fe}_{3} \mathrm{O}_{4}$ [41], $\mathrm{RGO}-\mathrm{Fe}_{3} \mathrm{O}_{4}$ [42,43], RGO- $\mathrm{MFe}_{2} \mathrm{O}_{4}(\mathrm{M}=\mathrm{Mn}$, $\mathrm{Zn}, \mathrm{Co}$ and $\mathrm{Ni}$ ) [44] and so on. Xie et al. [41] fabricated GO- $\mathrm{Fe}_{3} \mathrm{O}_{4}$ hybrids by depositing amino-functionalized $\mathrm{Fe}_{3} \mathrm{O}_{4}$ on the surface of GO. The hybrids showed the adsorption capacities of $0.167 \mathrm{~g} \mathrm{~g}^{-1}$ for methylene blue and $0.171 \mathrm{~g} \mathrm{~g}^{-1}$ for neutral red, and it can be easily seperated by external magnetic filed after adsorption. Fan et al. [45] synthesized magnetic chitosan/GO (MCGO) composite. The MCGO can be used as a magnetic adsorbent towards methylene blue with higher adsorption capacity $\left(0.18 \mathrm{~g} \mathrm{~g}^{-1}\right)$, fast adsorption rates, and excellent separation properties. Based on this research, magnetic $\beta$-cyclodextrin-chitosan/ GO (MCCG) was synthesised in their later research. This adsorbent had good and versatile adsorption capacity to the dyes due to the synergistic effect of the surface property of GO, hydrophobicity of $\beta$-cyclodextrin, the abundant amino and hydroxyl functional groups of chitosan and the magnetic property of $\mathrm{Fe}_{3} \mathrm{O}_{4}$ [46]. More importantly, it can be regenerated easily and rapidly. Liu and co-workers [47] reported that a $3 \mathrm{D}$ GO sponge displayed the high adsorption

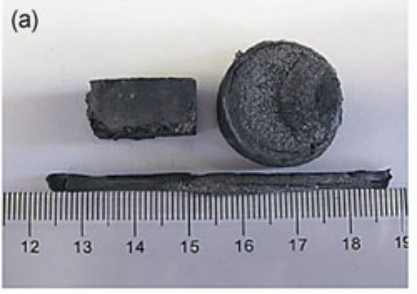

(d)

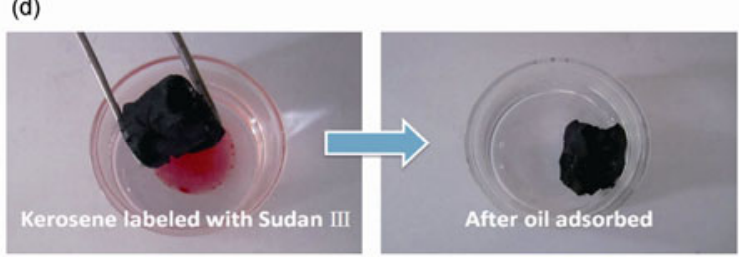

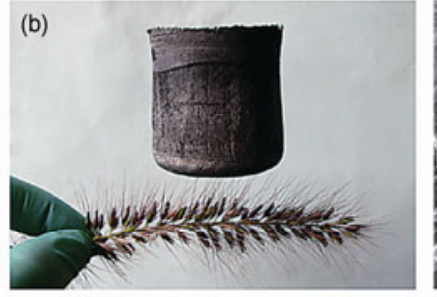

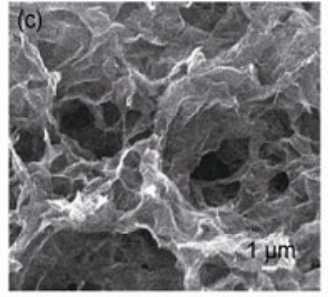

(e)

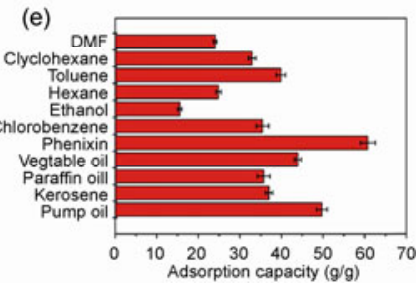

Figure 3 (Color online) (a), (b) Macroscopic structures of ultra-flyweight aerogels with diverse shapes. Reprinted from ref. [34] with permission from the WILEY-VCH Verlag GmbH \& Co. kGaA, Weinheim; (c) SEM image; (d) photograph of the kerosene labeled with Sudan III adsorption; (e) adsorption capacities for different oils and organic solvents at saturated state of GaA-GA. Reprinted from ref. [35] with permission from the Royal Society of Chemistry. 
capacity of $0.397 \mathrm{~g} \mathrm{~g}^{-1}$ for methylene blue and $0.467 \mathrm{~g} \mathrm{~g}^{-1}$ for methylene violet due to the strong $\pi-\pi$ stacking and anion-cation interaction between dyes and 3D GO sponge. For the removal of dyes. another technology used widely is photocatalytic degradation, and many highly efficiency graphene-based photocatalyst such as $\mathrm{ZnO} / \mathrm{RGO}$ [48-50], CdS/RGO [51,52], $\mathrm{TiO}_{2} / \mathrm{RGO}$ [53-55] have been reported. More recently, Khan et al. [56] improved the photocatalytic activity of $\mathrm{CdS} / \mathrm{ZnO}$ and $\mathrm{CdS} / \mathrm{Al}_{2} \mathrm{O}_{3}$ by combining with $\mathrm{GO}$. The obtained $\mathrm{CdS} / \mathrm{ZnO} / \mathrm{GO}$ and $\mathrm{CdS} / \mathrm{Al}_{2} \mathrm{O}_{3} / \mathrm{GO}$ exhibited highly efficient photodegradation toward methyl orange ( $\sim 99 \%$ for $\mathrm{CdS} / \mathrm{ZnO} / \mathrm{GO}$ while $\sim 90 \%$ for $\mathrm{CdS} / \mathrm{Al}_{2} \mathrm{O}_{3} / \mathrm{GO}$ within $60 \mathrm{~min})$.

In addition, graphene and its derivatives can be applied to the removal of pesticides $[57,58]$ and phenolic compunds $[59,60]$. For example, Liu and co-workers [58] presented graphene-coated silica can achieve higher levels of adsorption for eleven organophosphorous pesticides than another five sorbens (graphite carbons, activated carbon, pure graphene, $\mathrm{C} 18$ silica, and silica). Graphene can be used as a sorbent of bisphenol $\mathrm{A}$, with the maximum adsorption capacity of $0.182 \mathrm{~g} \mathrm{~g}^{-1}$ [59]. Table 1 shows the preparation and application of different graphene-based materials in the adsorption of metal ions and dyes.

\section{Functionalized graphene for environmental detection}

\subsection{Detection for toxic gases in air}

The detection of gas molecules is necessary in many fields especially environmental monitoring due to theirs toxicity and risk. Recently, many gas sensors based on graphene have been devised because of the advantages of graphene such as high electron mobility, large surface-to-volume ratio and low electrical noise, and the sensing mechanism is mainly attributed to the change in the conductance or resistance of graphene caused by the charge transfer between adsorbed gas molecules and graphene sheets.

Wang et al. [61] used partially RGO thin film prepared by thermal treatment (at $500^{\circ} \mathrm{C}$ in a vacuum) as an active sensing element to develop a hydrogen gas sensor, which exhibited fast response time $(\sim 20 \mathrm{~s})$, good sensitivity $(\sim 4.5 \%)$ and quick recovery time $(\sim 10 \mathrm{~s})$ to $0.16 \mathrm{~g} \mathrm{~g}^{-1}$ of hydrogen gas at room temperature. Based on chemically RGO, Lu et al. [62] fabricated a room temperature gas sensor for detecting low-concentration $\mathrm{NO}_{2}\left(0.10 \mathrm{~g} \mathrm{~L}^{-1}\right)$ and $\mathrm{NH}_{3}(1 \%)$ in air. Meanwhile, Dua et al. [63] devoloped a chemiresistor to detect chemically aggressive vapors $\mathrm{NO}_{2}$ and $\mathrm{Cl}_{2}$ reversibly and selectively. The sensitivity of gas

Table 1 The preparation and application of different graphene-based materials in the adsorption of metal ions and dyes

\begin{tabular}{|c|c|c|c|}
\hline Graphene-based materials & Analytes & Preparation & References \\
\hline Graphene nanosheets & $\mathrm{Pb}^{2+}, \mathrm{Cd}^{2+}, \mathrm{Co}^{2+}, \mathrm{U}^{5+}$ & Vacuum-promoted low-temperature exfoliation of graphene & {$[11,15,16]$} \\
\hline GO aerogel & $\mathrm{Cu}^{2+}$ & Unidirectional freeze-drying of GO suspension & [14] \\
\hline $\begin{array}{l}\text { Magnetic graphene } \\
\text { composites }\end{array}$ & $\begin{array}{l}\mathrm{Cu}^{2+}, \mathrm{Cd}^{2+}, \mathrm{Pb}^{2+} \\
\mathrm{Co}^{2+}\end{array}$ & In situ coprecipitation of $\mathrm{Fe}^{3+}$ and $\mathrm{Fe}^{2+}$ in the presence of $\mathrm{GO}$ & {$[17,18,28,29]$} \\
\hline $\begin{array}{l}\text { Metal oxides/graphene } \\
\text { nanosheets }\end{array}$ & $\mathrm{Cu}^{2+}, \mathrm{Pb}^{2+}, \mathrm{Cr}^{6+}$ & $\begin{array}{l}\delta-\mathrm{MnO}_{2} \text { reduction via a microwave-assisted method; } \mathrm{UV} \text {-assisted photocatalytic } \\
\text { reduction of } \mathrm{GO} \text { by } \mathrm{ZnO} \text { nanoparticles in ethanol; } \mathrm{Fe}^{2+} \text { as reducing agent for the } \\
\text { reduction of } \mathrm{GO} \text {; In situ depositing } \mathrm{TiO}_{2} \text { nanoparticles on } \mathrm{GO} \text { nanosheets }\end{array}$ & {$[20,23,25,27,30]$} \\
\hline $\begin{array}{l}\text { Polypyrrole-reduced GO } \\
\text { composite }\end{array}$ & $\mathrm{Hg}^{2+}$ & Reduction by hydrazine hydrate & {$[31]$} \\
\hline $\begin{array}{l}\text { Ethylenediaminetetraacetc } \\
\text { acid-GO }\end{array}$ & $\mathrm{Pb}^{2+}, \mathrm{Cr}^{6+}$ & $\begin{array}{l}\text { Silanization reaction of } N \text {-(trimethoxysilylpropyl) ethylenediamine triacetic acid } \\
\text { and GO in ethanol solution }\end{array}$ & {$[32,33]$} \\
\hline Polyethersulfone/GO & $\begin{array}{l}\text { Methylene blue } \\
\text { Methyl violet }\end{array}$ & Liquid-liquid phase separation technique & {$[39,40]$} \\
\hline $\begin{array}{l}\text { Reduced } \mathrm{GO}-\mathrm{MFe}_{2} \mathrm{O}_{4} \\
\text { hybrids }\end{array}$ & $\begin{array}{l}\text { Rhodamine B } \\
\text { Methylene blue }\end{array}$ & $\begin{array}{l}\text { One-pot solvothermal method using ethylene glycol as medium with controlled } \\
\text { amount of } \mathrm{GO}, \mathrm{Fe}^{3+} \text { and } \mathrm{Mn}^{2+}, \mathrm{Zn}^{2+}, \mathrm{Co}^{2+} \text { or } \mathrm{Ni}^{2+}\end{array}$ & [44] \\
\hline Chitosan/GO composites & Methylene blue & Amidation reaction between GO and magnetic chitosan & [45] \\
\hline$\beta$-cyclodextrin-chitosan/GO & Methylene blue & $\begin{array}{l}\text { Mixing and sonicating magnetic } \beta \text {-cyclodextrin-chitosan, GO and glutaraldehyde, } \\
\text { followed by stirring the mixture at } 65^{\circ} \mathrm{C}\end{array}$ & [46] \\
\hline GO sponge & $\begin{array}{l}\text { Methylene blue } \\
\text { Methyl violet }\end{array}$ & Centrifugal vacuum evaporation of GO suspension & [47] \\
\hline $\begin{array}{l}\text { Reduced } \mathrm{GO} / \mathrm{ZnO} \\
\text { nanohybrids }\end{array}$ & $\begin{array}{l}\text { Rhodamine B } \\
\text { Methylene blue }\end{array}$ & $\begin{array}{l}\text { Depositing } \mathrm{ZnO} \text { nanocrystals on reduced GO sheets via microwave-assisted route } \\
\text { in diethylene glycol }\end{array}$ & [48] \\
\hline Reduced GO/CdS hybrid & Methylene blue & $\begin{array}{l}\text { One-step solvothermal method using dimethylsulfoxide as medium with controlled } \\
\text { amount of GO and } \mathrm{Cd}^{2+}\end{array}$ & {$[51,52,56]$} \\
\hline $\begin{array}{l}\text { Reduced GO- } \mathrm{TiO}_{2} \\
\text { composites }\end{array}$ & Methyl orange & $\begin{array}{l}\text { In situ liquid phase depositing } \mathrm{TiO}_{2} \text { on } \mathrm{GO} \text {, followed by thermal reduction in } \mathrm{N}_{2} \\
\text { atmosphere. }\end{array}$ & [53] \\
\hline
\end{tabular}


sensors can be further enhanced by modifying the graphene with catalytic metals such as $\mathrm{Pt}, \mathrm{Pd}$ and $\mathrm{Au}$, and many platforms of sensing different toxic gases have been reported by this method [64-67]. For instance, Li and co-workers [66] developed a graphene-based device of detecting NO by alternating current dielectrophoresis. This sensor composed of sensing channels of palladiumdecorated RGO and the electrodes covered with chemical vapor deposition-grown graphene, and the procedure of fabrication and test is shown in Figure 4(a). Although it had a detection range from $2 \times 10^{-6}$ to $4.2 \times 10^{-4} \mathrm{~g} \mathrm{~L}^{-1}$ for $\mathrm{NO}$ and improved sensitivity and stability, it needed an extremely long recovery time, and was almost irrecoverable. In order to overcome this problem, current annealing was applied to the sensor and a $\sim 1000 \mathrm{~s}$ recovery time was obtained at $2 \times 10^{-6} \mathrm{~g} \mathrm{~L}^{-1} \mathrm{NO}$ concentration, which is shown in Figure 4(b).

More recently, graphene functionalized with semiconductor metal oxidess, especially $\mathrm{TiO}_{2}$ [68], $\mathrm{SnO}_{2}$ [69], $\mathrm{ZnO}$ [70], $\mathrm{Cu}_{2} \mathrm{O}$ [71,72], and $\mathrm{WO}_{3}$ [73] spark intense research interest and have been applied to gas-sensing. For example, Mao et al. [69] reported a gas-sensing platform with RGO decorated with tin oxide nanocrystals $\left(\mathrm{RGO}-\mathrm{SnO}_{2}\right)$, which displayed improved $\mathrm{NO}_{2}$ but weakened $\mathrm{NH}_{3}$ sensing compared with the single RGO. An et al. [73] assembled single crystalline $\mathrm{WO}_{3}$ nanorods on the surface of graphene, and the obtained $\mathrm{WO}_{3}$ /graphene nanocomposites exhibited superor sensitivity and selectivity to $\mathrm{NO}_{2}$ due to the unique properties of this new material, such as the improved conductivity, specific electron transfer and increased gas adsorption. For the detection of $\mathrm{H}_{2} \mathrm{~S}$, Zhou and co-workers [71] designed a sensor using $\mathrm{Cu}_{2} \mathrm{O}$ nanocrystals grown on functionalized graphene sheets $\left(\mathrm{Cu}_{2} \mathrm{O} / \mathrm{FGS}\right)$ as a conducting channel. The synthesis of $\mathrm{Cu}_{2} \mathrm{O} / \mathrm{FGS}$ and the mechanism of sensing $\mathrm{H}_{2} \mathrm{~S}$ are shown in Figure 4(c) and (d). $\mathrm{H}_{2} \mathrm{~S}$ can be chemisorbed on the $\mathrm{Cu}_{2} \mathrm{O}$ at room temperature when the $\mathrm{Cu}_{2} \mathrm{O}$ decorated on the FGS encounters $\mathrm{H}_{2} \mathrm{~S}$, which lead to the transfer of electrons from $\mathrm{H}_{2} \mathrm{~S}$ to $\mathrm{Cu}_{2} \mathrm{O}$ and the decrease of hole carrier density causing the increase of resistance. This sensor demonstrated fantastic sensitivity $(11 \%)$ even at the lower concentration of $5 \times 10^{-6} \mathrm{~g} \mathrm{~L}^{-1}$ (Figure 4(e)), due to the synergistic effect of $\mathrm{Cu}_{2} \mathrm{O}$ (higher surface activity) and FGS (greater electron transfer efficiency). In addition, gas sensor based on graphene decorated with polymer have
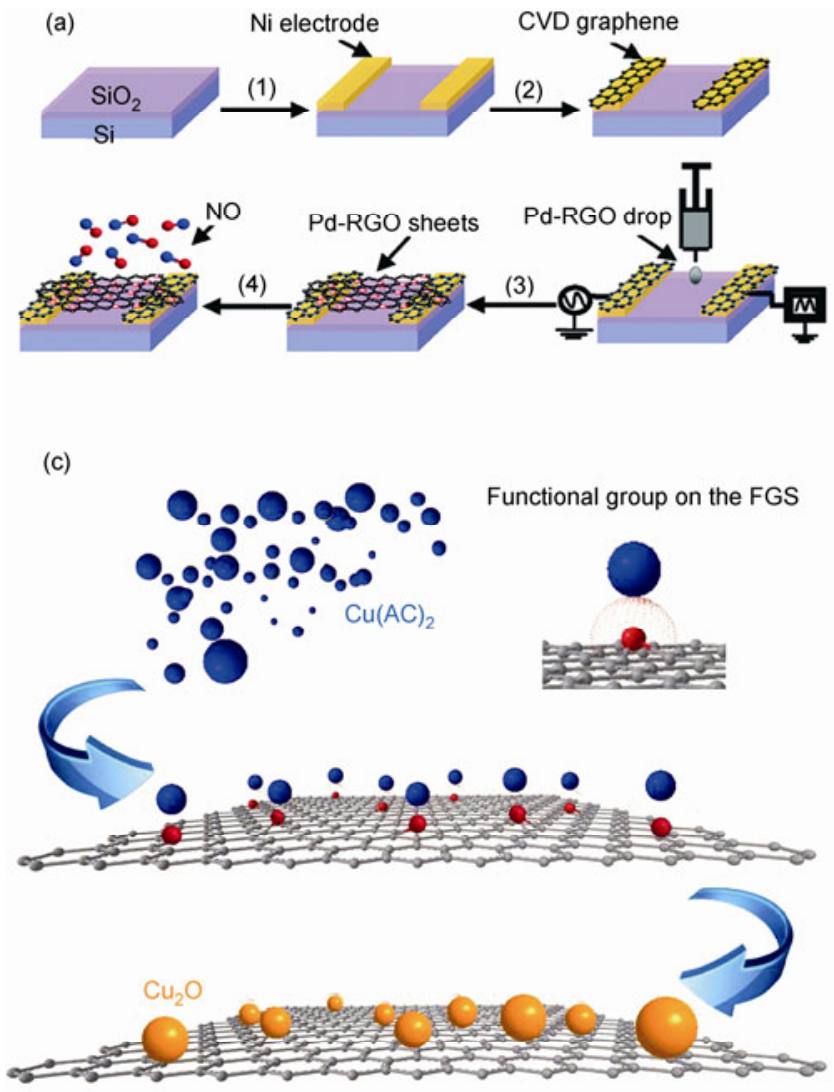

(b)

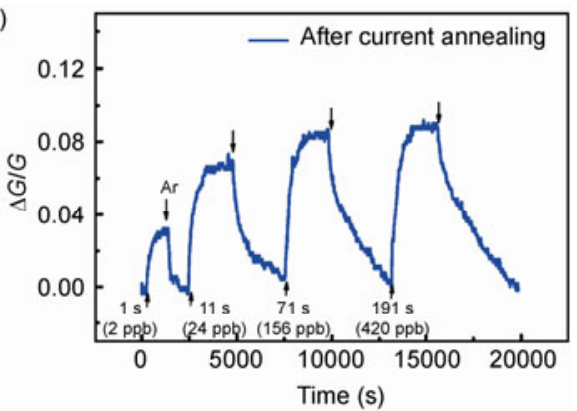

(d)
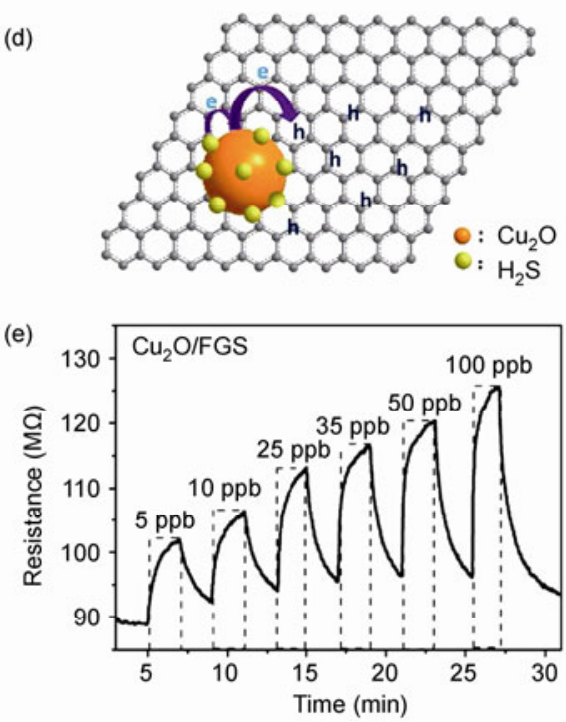

Figure 4 (Color online) (a) Schematics of graphene-Pd-RGO device fabrication and gas sensing test. (b) The response of the sensor to different concentrations of NO. To decrease the recovery time, Ar and current annealing are used. Reprinted from ref. [66] with permission from the American Chemical Society. (c) The schematic illustration of in situ synthesis of $\mathrm{Cu}_{2} \mathrm{O} / \mathrm{FGS}$. (d) $\mathrm{The}_{2} \mathrm{~S}$ sensing mechanism and (e) the dynamic $\mathrm{H}_{2} \mathrm{~S}$ sensing behaviour of the $\mathrm{Cu}_{2} \mathrm{O} / \mathrm{FGS}$-based sensor. Reprinted from ref. [71] with permission from the Elsevier Science Ltd. 
been repoted $[74,75]$.

\subsection{Detection for heavy metal ions}

The maximum contamination level of heavy metal ions in ambience especially in drinking water, are defined clearly by EPA (U.S. Environmental Protection Agency) and WHO (World Health Organization) due to their high toxicity. Therefore, it is urgent to develop highly sensitive and well selective devices for the detection of heavy metal ions. Currently, many platforms based on graphene and its derivatives have been constructed due to the extraordinary optical property and excellent electrical conductivity of graphene.

Fluorescence resonance energy transfer (FRET)-based sensors are explored by a number of research groups, due to the ability of graphene to quench fluorescence. For example, Fu et al. [76] developed a "turn-on" fluorescence sensor based on graphene-gold nanoparticles (AuNPs) to detect $\mathrm{Pb}^{2+}$ in aqueous solution, which was attributed to the accelerated leaching rate of AuNPs by adding $\mathrm{Pb}^{2+}$. AuNPs on the surface of graphene would form complexes $\mathrm{Au}\left(\mathrm{S}_{2} \mathrm{O}_{3}\right)_{2}{ }^{3-}$ in thiosulfate liquors. Then, the $\mathrm{Au}\left(\mathrm{S}_{2} \mathrm{O}_{3}\right)_{2}{ }^{3-}$ was dissolved rapidly to form $\mathrm{Au}(2-\mathrm{ME})_{2-}$ after adding $\mathrm{Pb}^{2+}$ and 2-ME, which lead to the rapid leaching of AuNPs from the graphene surfaces (Figure 5(a)). As a result, the fluorescence of graphene quenched by AuNPs would reappear and increase, and the relative fluorescence intensity displayed a good linearity against logarithm concentration of $\mathrm{Pb}^{2+}$, as shown in Figure 5(b). The result revealed that this platform had a higher detection limit of $1.0 \times 10^{-8} \mathrm{~mol} \mathrm{~L}^{-1}$ and more excellent selectivity over common metal ions such as $\mathrm{Al}^{3+}, \mathrm{Ca}^{2+}$, $\mathrm{Cd}^{2+}, \mathrm{K}^{+}, \mathrm{Mg}^{2+}, \mathrm{Zn}^{2+}, \mathrm{Li}^{+}, \mathrm{Co}^{2+}, \mathrm{Ni}^{2+}, \mathrm{Hg}^{2+}, \mathrm{Cu}^{2+}, \mathrm{Ag}^{+}, \mathrm{Mn}^{2+}$, $\mathrm{Cr}^{3+}$, and $\mathrm{Fe}^{2+}$. It will have a promising application in environmental monitoring. Considering the advantages of the photoluminescence of quantum dots (QDs), such as a high quantum yield, low photobleaching and size-dependent and tunable adsorptions and emissions, Li's group [77] constructed another one "turn-on" fluorescent biosensor based on the energy transfer from CdSe/ZnS QDs to GO. This sensor exhibited a limit of detection as low as 9.0× $10^{-11} \mathrm{~mol} \mathrm{~L}^{-1}$ toward $\mathrm{Pb}^{2+}$ with excellent selectivity, and it is proved to be applied in river water sample.

Functional nucleic acids have more flexibility as molecular recognition tools, and many fluorescence sensors are designed based on this advantage. Liu et al. [78] presented a
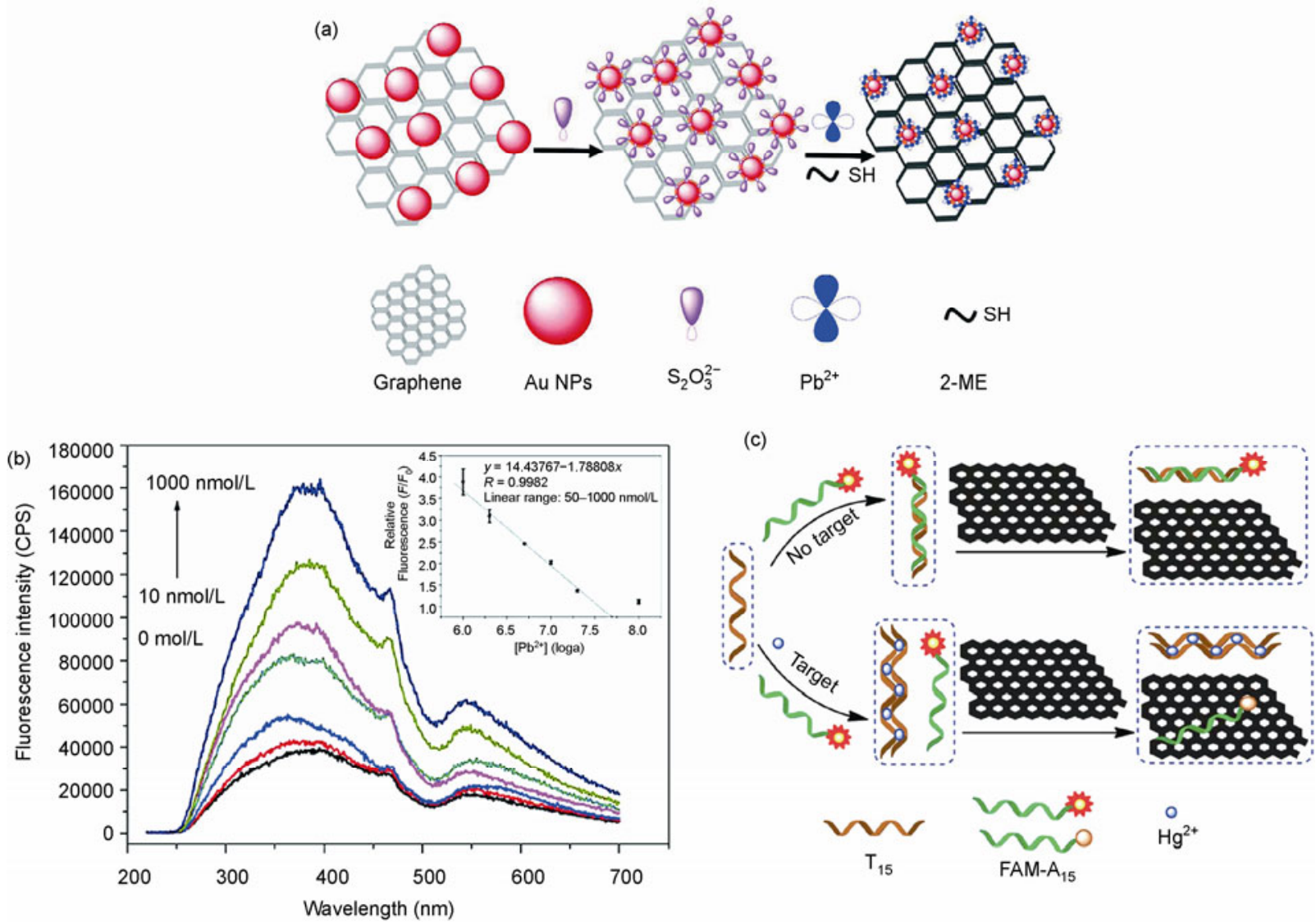

Figure 5 (Color online) (a) The sensing mechanism for $\mathrm{Pb}^{2+}$ and (b) the fluorescence spectra of $\mathrm{Pb}^{2+}\left(0-1.0 \times 10^{-6}\right.$ mol $\left.\mathrm{L}^{-1}\right)$ of $\mathrm{G}-\mathrm{AuNCs}$. Reprinted from ref. [76] with permission from the American Chemical Society. (c) The schematic illustrating the fluorescence detection of $\mathrm{Hg}^{2+}$ based on DNA duplexes of poly(dT) and GO. Reprinted from ref. [82] with permission from Royal Society of Chemistry. 
sensor for the detection of $\mathrm{Ag}^{+}$. Based on the interactions between the fluorogenic silver-specific cytosine-rich oligonucleotide and GO, Wen et al. [79] designed a fluorescent sensor to detect $\mathrm{Ag}^{+}$with a limit of detection of $5.0 \times 10^{-9} \mathrm{~mol} \mathrm{~L}^{-1}$. In their later research, they used GO and $\mathrm{Pb}^{2+}$-dependent DNAzyme to develop a nanoprobe for fluorescent detection of $\mathrm{Pb}^{2+}$ [80]. Meanwhile, A selfassembled DNA-GO-based fluorescent platform was developted to detect $\mathrm{Ag}^{+}$and $\mathrm{Hg}^{+}$with the lower concentrations of $2.0 \times 10^{-8}$ and $5.7 \times 10^{-9} \mathrm{~mol} \mathrm{~L}^{-1}$ respectively [81]. More recently, Zhang et al. [82] reported a highly sensitive, selective, and rapid method for fluorescence detection of $\mathrm{Hg}^{2+}$ for the first time. It was based on DNA duplexes of poly(dT) and GO, and the mechanism of detecion is shown in Figure 5(c). Withouting $\mathrm{Hg}^{2+}$, the target probe $\mathrm{T}_{15}$ would form double-stranded DNA by hybridizing with $\mathrm{A}_{15}$ labelled with 6'-carboxy fluorescein $\left(\mathrm{FAM}-\mathrm{A}_{15}\right)$, and the FAM exhibited strong fluorescence. Upon adding $\mathrm{Hg}^{2+}, \mathrm{FAM}^{2} \mathrm{~A}_{15}$ wouldl be in a single-stranded state because of the formation of DNA duplexes of poly(dT), and it would result in the fluorescence quenching of FAM by binding GO. Basd on the linearity of the intensity of fluorescence against the concentration of $\mathrm{Hg}^{2+}$, this sensor had a detection limit of $5.0 \times 10^{-10} \mathrm{~mol} \mathrm{~L}^{-1}$, and could be used in river water samples.

Compared with fluorescence detections, electrochemical methods attract considerable attention for the advantages of fast, portability, high-sensitivity, and low cost in recent years. Among the electrochemical techniques, potentiometry and voltammetry are employed widely.

In potentiometric sensors, filed effect transistor (FET)based sensors are developed rapidly. For example, Sudibya and co-workers [83] introduced a nanoscale FET sensor, using micropatterned, protein-functionalized RGO films as the sensing channel. This RGO-FETs were able to detect $\mathrm{Ca}^{2+}, \mathrm{Mg}^{2+}, \mathrm{Hg}^{2+}$ and $\mathrm{Cd}^{2+}$ via the change of conductance caused by the adding of target metal ions. Considering the relatively complex fabrication procedure of protein-based FET sensors, Chen et al. [84] fabricated a FET based on thermally RGO decorated with thioglycolic acid(TGA) functionalized gold nanoparticles for the detection of $\mathrm{Hg}^{2+}$, and the schematic diagram was displyed in Figure 6(a). The sensor showed a lower detection limit $\left(2.5 \times 10^{-8} \mathrm{~mol} \mathrm{~L}^{-1}\right)$ and faster responses (less than $10 \mathrm{~s}$ ) (Figure 6(b)), and it would be a promising detector of $\mathrm{Hg}^{2+}$ providing fast, realtime, simple detection with high sesitivity and selectivity.

In the voltammetric techniques, anodic stripping voltammetry is the most frequently used for the detection of heavy metal ions due to the high sensitivity and selectivity. Based on this method, many electrochemical detection devices are constructed using graphene decorated with molecules possessing affinity toward certain heavy metal ions as electrode materials. For instance, the highly selective adsorption of polypyrrole/RGO to $\mathrm{Hg}^{2+}$ was reported by Zhao's group [85]. Based on this discovery, they fabricated an electrochemical sensor for the detection of $\mathrm{Hg}^{2+}$ with the detection limit of $1.5 \times 10^{-8} \mathrm{~mol} \mathrm{~L}^{-1}$, and the schematic of selective detection is shown in Figure 7. A more sensitive method for detecting $\mathrm{Hg}^{2+}$ was presented by Zhou et al. [86], based on GO decorated with cysteamine and had lower detection limit of $3.0 \times 10^{-9} \mathrm{~mol} \mathrm{~L} \mathrm{~L}^{-1}$. More importantly, this sensor demonstrated excellent selectivity towards $\mathrm{Hg}^{2+}$ in the presence of $\mathrm{Cu}^{2+}, \mathrm{Co}^{2+}, \mathrm{Fe}^{2+}, \mathrm{Zn}^{2+}$ and $\mathrm{Mn}^{2+}$ with a 200 times higher concentration of $\mathrm{Hg}^{2+}$.

For simultaneous detection of several heavy metal ions, Wei et al. [87] prepared a sensor based on $\mathrm{SnO}_{2} / \mathrm{RGO}$ nanocomposite for the simultaneous detection of $\mathrm{Cd}^{2+}, \mathrm{Pb}^{2+}$, $\mathrm{Cu}^{2+}$ and $\mathrm{Hg}^{2+}$ by square wave anodic stripping voltammetry (SWASV). Compared with the bare and other glassy carbon electrodes modified with GO, the electrode modified with $\mathrm{SnO}_{2} / \mathrm{RGO}$ exhibited improved selectivity and sensitivity to the four heavy metal ions. Gao et al. [88] developed a platform of simultaneously detecting $\mathrm{Pb}^{2+}$ and $\mathrm{Cd}^{2+}$, using $\mathrm{AlOOH}-\mathrm{RGO}$ nanocomposites as the sensing material. The limit of detection (LOD) is $4.46 \times 10^{-11} \mathrm{~mol} \mathrm{~L}^{-1}$ for $\mathrm{Cd}^{2+}$ and $7.60 \times 10^{-11} \mathrm{~mol} \mathrm{~L}{ }^{-1}$ for $\mathrm{Pb}^{2+}$ respectively, and this sensor is proved to be highly sensitive and well stable. More recently, Ion and co-workers [89] presented an aminofunctionalized exfoliated graphite nanoplatelet-based electrochemical sensor for the detection of $\mathrm{Pb}^{2+}$ with a detection limit of $1.0 \times 10^{-9} \mathrm{~g} \mathrm{~L}^{-1}$, being lower than the
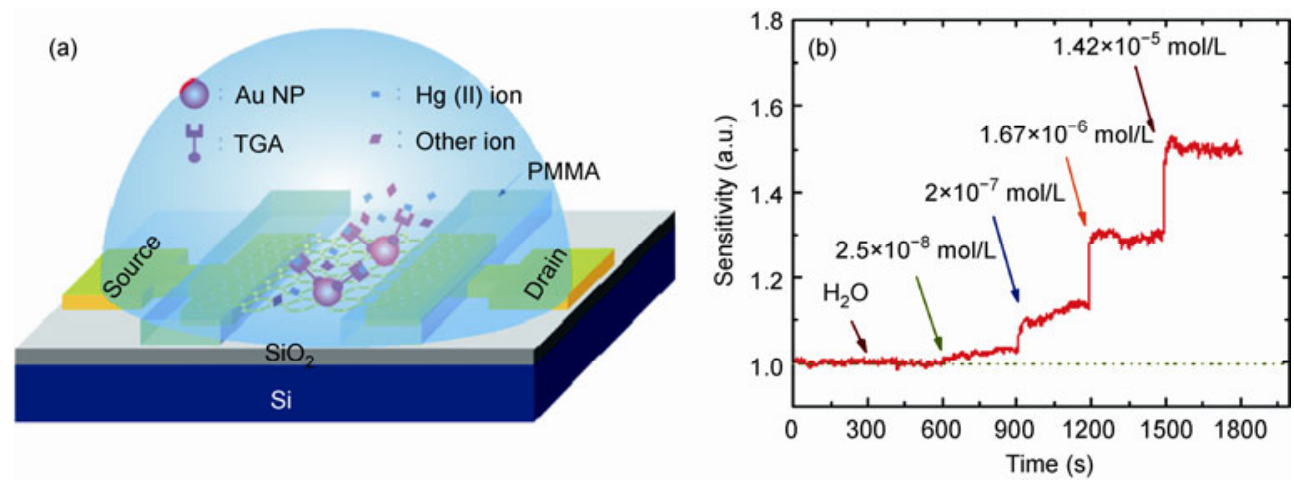

Figure 6 (Color online) (a) The schematic diagram and (b) the dynamic response for $\mathrm{Hg}^{2+}$ of the rGO/TGA-AuNP hybrid sensor. Reprinted from ref. [84] with permission from the American Chemical Society. 


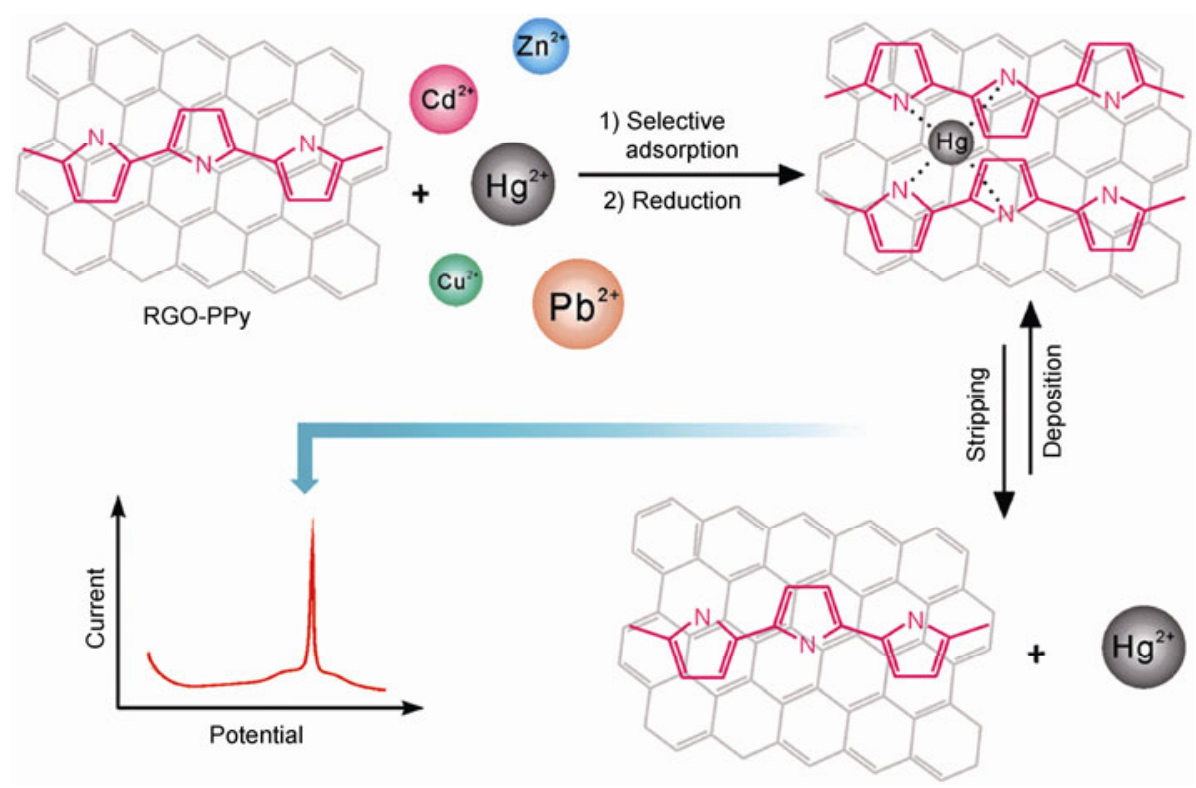

Figure 7 (Color online) A schematic drawing of $\mathrm{Hg}^{2+}$ electrochemically selective detection by the PPy-RGO nanocomposite. Reprinted from ref. [85] with permission from the Royal Society of Chemistry.

previous reports.

\subsection{Detection for organic pollutants}

Among the organic pollutants, phenolic compounds, as raw materials of dyes, cosmetics and pesticides, are used widely in chemical and pharmaceutical industries and the maximum level permitted is defined strictly by the wastewater discharge standard. Furthermore, dyes and pesticides are also limited due to their risk to human health and environment. Therefore, the qualitative and quantitative anaysis of these pollutants are of great importance.

For the detection of phenolic compounds, Li et al. [90] constructed an electrochemical sensor for simultaneous detection of dihydroxybenzene isomers, using thermally RGO as a electrocatalyst. This sensor demonstrated the detection limits of $7.5 \times 10^{-7} \mathrm{~mol} \mathrm{~L}^{-1}$ for hydroquinone, and $8.0 \times 10^{-7} \mathrm{~mol} \mathrm{~L}^{-1}$ for catechol. At present, modification of graphene with functional small molecules having specific interaction with the target analytes is a good approach to enhance the selectivity and sensitivity of electrochemical detection. Cyclodextrin causes great interest in many research groups because of its unique structural properties, which can bind selectively many kinds of inorganic, organic and biological molecules into its cavities. Therfore, many sensors based on graphene and cyclodextrin have been developed rapidly. Recently, our group [91] synthesized hydroxypropyl- $\beta$-cyclodextrin modified GNSs (HP- $\beta$-CD$\mathrm{RGO})$ by the esterification of $\mathrm{GO}$ carboxyl(- $\mathrm{COOH})$ with the hydroxyl $(-\mathrm{OH})$ of $\mathrm{HP}-\beta-\mathrm{CD}$ under microwave irradiation in water medium. This nanocomposite possessed high surface area and excellent supermolecular recognition, and the synthesis procedure and the interaction between host and guest are shown in Figure 8. More important, the HP- $\beta$-CD-RGO modified glassy carbon electrode exhibited high electrochemical response to six phenolic organic pollutants, and had a detection limit of $1 \times 10^{-8} \mathrm{~mol} \mathrm{~L}^{-1}$ for nitrophenol. Later, Liu and co-workers [92] used $\beta$-CDRGO to detect simultaneously nitrophenol isomers. Zhu et al. [93] applied $\beta$-cyclodextrin-platinum nanoparticles/ graphene nanohybrids to the selective detection of naphthol isomers. More recently, graphene-based electrochemical enzyme biosensors are devised [94,95]. Wu et al. [96] demonstrated a graphene-based tyrosine biosensor for the determination of bisphenol $\mathrm{A}$ and it displayed superior analytical performance with sensitivity of $31084 \mathrm{~A} \mathrm{~m}^{-2} \mathrm{M}^{-1}$ and detection limit of $3.3 \times 10^{-8} \mathrm{~mol} \mathrm{~L}^{-1}$. In addition, graphene decorated with copper oxide [97], poly(3,4ethylenedioxythiophene) [98] and polydopamine [99] also can be applied to the detection of phenolic pollutants.

Concerning the detection of pesticides especially organophosphate pesticides, Wang et al. [100] selfassembled acetylcholinesteraseon on gold nanoparticles/ chemically RGO in the presence of poly(diallyldimethylammonium chloride) stabilizing cholinesterase with high activity and loading efficiency as well as enhancing the dispersion of AuNPs. The obtained composites were utilized as the catalyst to detect paraoxon, and it showed a low detection limit of $1.0 \times 10^{-13} \mathrm{~mol} \mathrm{~L} \mathrm{~L}^{-1}$. With the similar method, Zhang and co-workers [101] prepared another RGO biosensor. The electrochemical measurements indicated that this sensor had rapid response and high sensitivity for the detection of monocrotophos with lower concentration of $1.0 \times 10^{-7} \mathrm{~g} \mathrm{~L}^{-1}$. In order to detect methyl parathion, two enzymeless sensors respectively based on GNSs decorated with zirconia nanoparticles [102] and 

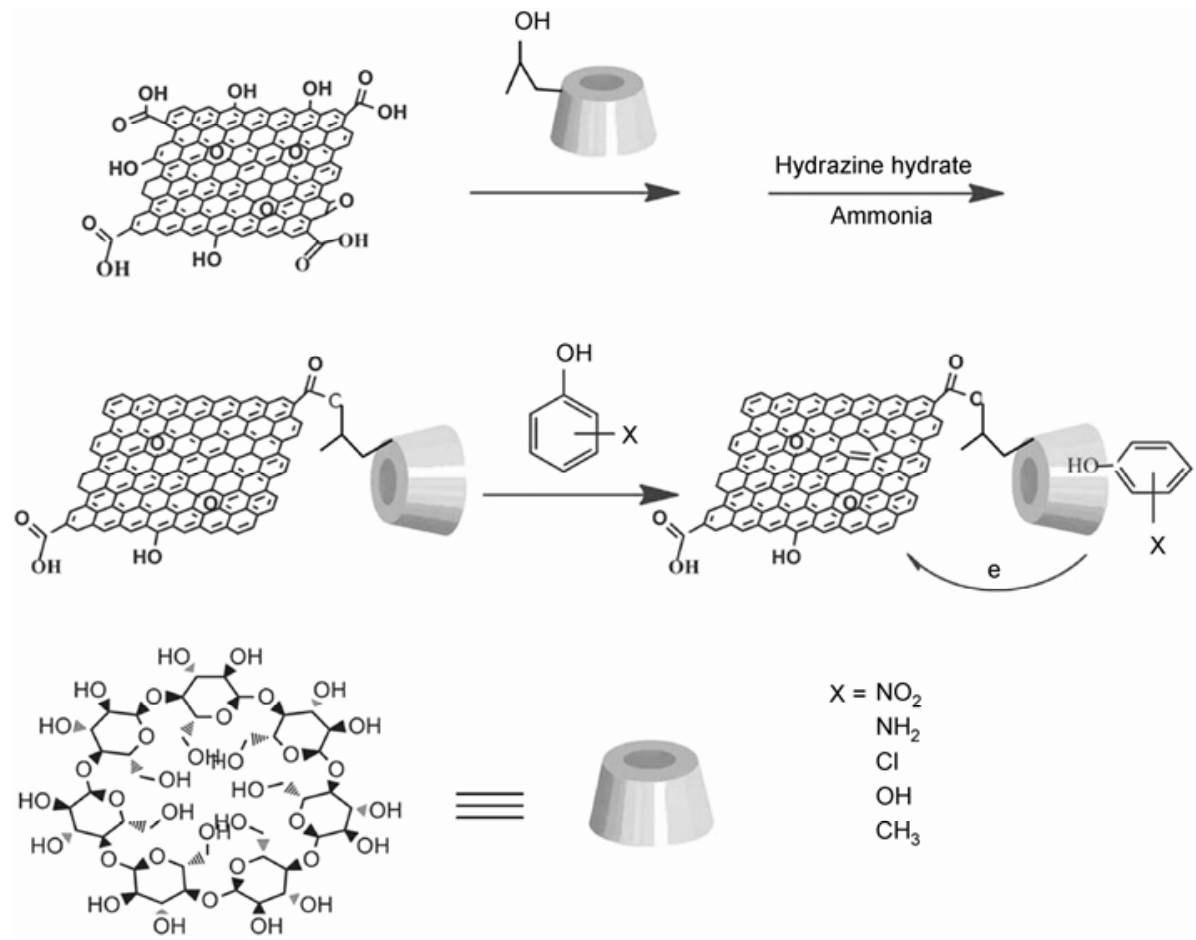

Figure 8 Schematic of the synthesis process of HP- $\beta$-CD-RGO composites and the interaction between the guest (o-nitrophenol) and the host (cyclodextrin moiety linked up to RGO). Reprinted from ref. [91] with permission from the Royal Society of Chemistry.

$\mathrm{Ni} / \mathrm{Al}$ layerd double hydroxides [103] were proposed and they had the same detection limit of $6.0 \times 10^{-7} \mathrm{~g} \mathrm{~L}^{-1}$. Furthermore, graphene-based voltammetric [104] and fluorescent [105] sensor of detecting various dyes and hydrogen peroxide [106] have been reported recently.

\section{Conclusions and perspectives}

We have summarized the latest studies and progresses on the application of graphene-based materials in the environmental protection and detection. With the unique structure and physicochemical properties, graphene has attracted much attention. Many efficient adsorbents and sensitive detection devices have been mentioned in this review. However, these achievements are still in the stage of laboratory investigation and few of them have been in commercial production for the treatment of large-scale industrial pollutions at present. In order to overcome these challenges, the future works should focus on the following issues. First, low-cost and simple methods for the synthesis of one or few layer graphene are urgently required. Second, more functional molecules, which have specific interaction with certain contaminants should be designed for improving the sensitivity and selectivity of the adsorbents and sensors. Third, more potential applications in environmental protection and detection remain to be discovered and investigated. With more and more efforts, we believe that graphene will have a more widely application prospect.
This work was supported by the National Natural Science Foundation of China (51272071), Specialized Research Fund for the Doctoral Program of Higher Education, Ministry of Education (20114208110005), Hubei Provincial Department of Education (D20111002, B2011802), and Wuhan Science and Technology Bureau (201271130447).

1 Stoller M D, Park S, Zhu Y W, et al. Graphene-based ultracapacitors. Nano Lett, 2008, 8: 3498-3502

2 Balandin A A, Ghosh S, Bao W, et al. Superior thermal conductivity of single-layer graphene. Nano Lett, 2008, 8: 902-907

3 Novoselov K S, Geim A K, Morozov S V, et al. Electric field effect in atomically thin carbon films. Science, 2004, 306: 666-669

4 Lee C, Wei X, Kysar J W, et al. Measurement of the elastic properties and intrinsic strength of monolayer graphene. Science, 2008, 321: $385-388$

5 He H K, Gao C. Graphene nanosheets decorated with Pd, Pt, Au, and Ag nanoparticles: Synthesis, characterization, and catalysis applications. Sci China Chem, 2011, 54: 397-404

6 Liu G L, Yu C L, Chen C C, et al. A new type of covalent-functional graphene donor-acceptor hybrid and its improved photoelectrochemical performance. Sci China Chem, 2012, 55: 1622-1626

7 Chang Y P, Ren C L, Qu J C, et al. Preparation and characterization of $\mathrm{Fe}_{3} \mathrm{O}_{4} /$ graphene nanocomposite and investigation of its adsorption performance for aniline and p-chloroaniline. Science, 2012, 261: 504-509

8 Khan Z, Chetia T R, Vardhaman A K, et al. Visible light assisted photocatalytic hydrogen generation and organic dye degradation by CdS-metal oxide hybrids in presence of graphene oxide. RSC Adv, 2012, 2: 12122-12128

9 Li J, Guo S J, Zhai Y M, et al. High-sensitivity determination of lead and cadmium based on the Nafion-graphene composite film. Anal Chim Acta, 2009, 649: 196-201

10 Wang D, Wang L, Dong X Y, et al. Chemically tailoring graphene oxides into fluorescent nanosheets for $\mathrm{Fe}^{3+}$ ion detection. Carbon, 2012, 50: 2147-2154 
11 Zheng H, Huang X Y, Zheng W, et al. Adsorption of lead(II) ions from aqueous solution on low-temperature exfoliated graphene nanosheets. Langmuir, 2011, 27: 7558-7562

12 Leng Y Q, Guo W L, Su S N, et al. Removal of antimony(III) from aqueous solution by graphene as an adsorbent. Chem Eng J, 2012, 211-212: 406-411

13 Song H J, Hao L Y, Tian Y F, et al. Stable and water-dispersible graphene nanosheets: Sustainable preparation, functionalization, and high-performance adsorbents for $\mathrm{Pb}^{2+}$. Chem Plus Chem, 2012, 77: 379-386

14 Mi X, Huang G B, Xie W S, et al. Preparation of graphene oxide aerogel and its adsorption for $\mathrm{Cu}^{2+}$ ions. Carbon, 2012, 50: 4856-4864

15 Zhao G X, Li J X, Ren X M, et al. Few-layered graphene oxide nanosheets as superior sorbents for heavy metal ion pollution management. Environ Sci Technol, 2011, 45: 10454-10462

16 Li Z J, Chen F, Yuan L Y, et al. Uranium(VI) adsorption on graphene oxide nanosheets from aqueous solutions. Chem Eng J, 2012, 210: 539-546

17 Zhang W J, Shi X H, Zhang Y X, et al. Synthesis of water-soluble magnetic graphene nanocomposites for recyclable removal of heavy metal ions. J Mater Chem A, 2013, 1: 1745-1753

18 Liu M C, Chen C L, Hu J, et al. Synthesis of magnetite/graphene oxide composite and application for cobalt(II) removal. J Phys Chem C, 2011, 115: 25234-25240

19 Ren Y M, Yan N, Fan Z J, et al. Graphene/ $\delta-\mathrm{MnO}_{2}$ composite as adsorbent for the removal of nickel ions from wastewater. Chem Eng J, 2011, 175: 1-7

20 Ren Y M, Yan N, Feng J, et al. Adsorption mechanism of copper and lead ions onto graphene nanosheet/ $\delta-\mathrm{MnO}_{2}$. Mater Chem Phys, 2012, 136: 538-544

21 Sun Y B, Chen C L, Tan X L, et al. Enhanced adsorption of Eu(III) on mesoporous $\mathrm{Al}_{2} \mathrm{O}_{3}$ /expanded graphite composites investigated by macroscopic and microscopic techniques. Dalton T, 2012, 41: 13388-13394

22 Zhang K, Kemp K C, Chandra V. Homogeneous anchoring of $\mathrm{TiO}_{2}$ nanoparticles on graphene sheets for waste water treatment. Mater Lett, 2012, 81: 127-130

23 Liu X J, Pan L K, Zhao Q F, et al. UV-assisted photocatalytic synthesis of $\mathrm{ZnO}$-reduced graphene oxide composites with enhanced photocatalytic activity in reduction of $\mathrm{Cr}(\mathrm{VI})$. Chem Eng J, 2012, 183: 238-243

24 Liu X J, Pan L K, Lv T, et al. Microwave-assisted synthesis of $\mathrm{ZnO}$-graphene composite for photocatalytic reduction of $\mathrm{Cr}(\mathrm{VI})$. Catal Sci Technol, 2011, 1: 1189-1193

25 Fan L L, Luo C N, Sun M, et al. Synthesis of graphene oxide decorated with magnetic cyclodextrin for fast chromium removal. J Mater Chem, 2012, 22: 24577-24583

26 Fan L L, Luo C N, Sun M, et al. Highly selective adsorption of lead ions by water-dispersible magnetic chitosan/graphene oxide composites. Colloid Surface B, 2013, 103: 523-529

27 Cong H P, Ren C X, Wang P, et al. Macroscopic multifunctional graphene-based hydrogels and aerogels by a metal ion induced self-assembly process. ACS Nano, 2012, 6: 2693-2703

28 Chandra V, Park J, Chun Y, et al. Water-dispersible magnetite-reduced graphene oxide composites for arsenic removal. ACS Nano, 2010, 4: 3979-3986

29 Bhunia P, Kim G, Baik C, et al. A strategically designed porous iron-iron oxide matrix on graphene for heavy metal adsorption. Chem Commun, 2012, 48: 9888-9890

30 Jiang G D, Lin Z F, Chen $\mathrm{C}$, et al. $\mathrm{TiO}_{2}$ nanoparticles assembled on graphene oxide nanosheets with high photocatalytic activity for removal of pollutants. Carbon, 2011, 49: 2693-2701

31 Chandra V, Kim K S. Highly selective adsorption of $\mathrm{Hg}^{2+}$ by a polypyrrole-reduced graphene oxide composite. Chem Commun, 2011, 47: 3942-3944

32 Madadrang C J, Kim H Y, Gao G H, et al. Adsorption behavior of EDTA-graphene oxide for $\mathrm{Pb}$ (II) removal. ACS Appl Mater Inter, 2012, 4: 1186-1193
33 Ma H L, Zhang Y W, Hu Q H, et al. Chemical reduction and removal of $\mathrm{Cr}(\mathrm{VI})$ from acidic aqueous solution by ethylenediamine-reduced graphene oxide. J Mater Chem, 2012, 22: 5914-5916

34 Sun H Y, Xu Z, Gao C. Multifunctional, ultra-flyweight, synergistically assembled carbon aerogels. Adv Mater, 2013, doi: 10.1002/ adma.201204576

35 Wang J L, Shi Z X, Fan J C, et al. Self-assembly of graphene into three-dimensional structures promoted by natural phenolic acids. J Mater Chem, 2012, 22: 22459-22466

36 Zhao J P, Ren W C, Cheng H M. Graphene sponge for efficient and repeatable adsorption and desorption of water contaminations. J Mater Chem, 2012, 22: 20197-20202

37 Bi H C, Xie X, Yin K B, et al. Spongy graphene as a highly efficient and recyclable sorbent for oils and organic solvents. Adv Funct Mater, 2012, 22: 4421-4425

38 Dong X C, Chen J, Ma Y W, et al. Superhydrophobic and superoleophilic hybrid foam of graphene and carbon nanotube for selective removal of oils or organic solvents from the surface of water. Chem Commun, 2012, 48: 10660-10662

39 Liu T H, Li Y H, Du Q j, et al. Adsorption of methylene blue from aqueous solution by graphene. Colloid Surface B, 2012, 90: 197-203

40 Zhang X, Cheng C, Zhao J, et al. Polyethersulfone enwrapped graphene oxide porous particles for water treatment. Chem Eng J, 2013, 215-216: 72-81

41 Xie G Q, Xi P X, Liu H Y, et al. A facile chemical method to produce superparamagnetic graphene oxide- $\mathrm{Fe}_{3} \mathrm{O}_{4}$ hybrid composite and its application in the removal of dyes from aqueous solution. J Mater Chem, 2012, 22: 1033-1039

42 Ai L H, Zhang C Y, Chen Z H, et al. Removal of methylene blue from aqueous solution by a solvothermal-synthesized graphene/ magnetite composite. J Hazard Mater, 2011, 192: 1515-1524

43 Sun H M, Cao L Y, Lu L H. Magnetite/reduced graphene oxide nanocomposites: One step solvothermal synthesis and use as a novel platform for removal of dye pollutants. Nano Res, 2011, 4: 550-562

44 Bai S, Shen X P, Zhong X, et al. One-pot solvothermal preparation of magnetic reduced graphene oxide-ferrite hybrids for organic dye removal. Carbon, 2012, 50: 2337-2346

45 Fan L L, Luo C N, Li X J, et al. Preparation of novel magnetic chitosan/graphene oxide composite as effective adsorbents toward methylene blue. Bioresource Technol, 2012, 114: 703-706

46 Fan L L, Luo C N, Sun M, et al. Synthesis of magnetic $\beta$-cyclodextrin-chitosan/graphene oxide as nanoadsorbent and its application in dye adsorption and removal. Colloid Surface B, 2013, 103: 601-607

47 Liu F, Chung S, Oh G, et al. Three-dimensional graphene oxide nanostructure for fast and efficient water-soluble dye removal. ACS Appl Mater Inter, 2012, 4: 922-927

48 Liu Y, Hu Y, Zhou M J, et al. Microwave-assisted non-aqueous route to deposit well-dispersed $\mathrm{ZnO}$ nanocrystals on reduced graphene oxide sheets with improved photoactivity for the decolorization of dyes under visible light. Appl Catal B: Environ, 2012, 125: 425-431

49 Fan H G, Zhao X T, Yang J H, et al. ZnO-graphene composite for photocatalytic degradation of methylene blue dye. Catal Commun, 2012, 29: 29-34

50 Pant H R, Park C H, Pokharel P, et al. ZnO micro-flowers assembled on reduced graphene sheets with high photocatalytic activity for removal of pollutants. Powder Technol, 2013, 235: 853-858

51 Wang X W, Tian H W, Yang Y, et al. Reduced graphene oxide/CdS for efficiently photocatalystic degradation of methylene blue. J Alloy Compd, 2012, 524: 5-12

52 Ye A H, Fan W Q, Zhang Q H, et al. CdS-graphene and CdS-CNT nanocomposites as visible-light photocatalysts for hydrogen evolution and organic dye degradation. Catal Sci Technol, 2012, 2: 969978

53 Pastrana-Martínez L M, Morales-Torres S, Likodimos V, et al. Advanced nanostructured photocatalysts based on reduced graphene oxide- $\mathrm{TiO}_{2}$ composites for degradation of diphenhydramine pharmaceutical and methyl orange dye. Appl Catal B: Environ, 2012, 123-124: 241-256

54 Liu S Z, Sun H Q, Liu S M, et al. Graphene facilitated visible light 
photodegradation of methylene blue over titanium dioxide photocatalysts.Chem Eng J, 2013, 241: 298-303

55 Liu S W, Liu C, Wang W G, et al. Unique photocatalytic oxidation reactivity and selectivity of $\mathrm{TiO}_{2}$-graphene nanocomposites. Nanoscale, 2012, 4: 3193-3200

56 Khan Z, Chetia T R, Vardhaman A K, et al. Visible light assisted photocatalytic hydrogen generation and organic dye degradation by CdS-metal oxide hybrids in presence of graphene oxide. RSC Adv, 2012, 2: 12122-12128

57 Maliyekkal M, Sreeprasad T S, Krishnan D, et al. Graphene: A reusable substrate for unprecedented adsorption of pesticides. Small, 2013, 9: 273-283

58 Liu X T, Zhang H Y, Ma Y Q, et al. Graphene-coated silica as a highly efficient sorbent for residual organophosphorus pesticides in water. J Mater Chem A, 2013, 1: 1875-1884

$59 \mathrm{Xu} \mathrm{J}$, Wang L, Zhu Y F. Decontamination of bisphenol A from aqueous solution by graphene adsorption. Langmuir, 2012, 28: 8418-8425

60 Ma H W, Shen j F, Shi M, et al. Significant enhanced performance for rhodamine $\mathrm{B}$, phenol and $\mathrm{Cr}(\mathrm{VI})$ removal by $\mathrm{Bi}_{2} \mathrm{WO}_{6}$ nancomposites via reduced graphene oxide modification. Appl Catal B: Environ, 2012, 121-122: 198-205

61 Wang J W, Kwak Y, Lee I, et al. Highly responsive hydrogen gas sensing by partially reduced graphite oxide thin films at room temperature. Carbon, 2012, 50: 4061-4067

62 Lu G H, Park S, Yu K, et al. Toward practical gas sensing with highly reduced graphene oxide: A new signal processing method to circumvent run-to-run and device-to-device variations. ACS Nano, 2011, 5: 1154-1164

63 Dua V, Surwade S P, Ammu S, et al. All-organic vapor sensor using inkjet-printed reduced grapheme oxide. Angew Chem Int Ed, 2010, 49: 2154-2157

64 Chu B H, Nicolosi J, Lo C F, et al. Effect of coated platinum thickness on hydrogen detection sensitivity of graphene-based sensors. Electrochem Solid ST, 2011, 14: 43-45

65 Johnson B J L, Behnam A, Pearton S J, et al. Hydrogen sensing using Pd-functionalized multi-layer graphene nanoribbon networks. Adv Mater, 2010, 22: 4877-4880

66 Li W W, Geng X M, Guo Y F, et al. Reduced graphene oxide electrically contacted graphene sensor for highly sensitive nitric oxide detection. ACS Nano, 2011, 5: 6955-6961

67 Gautam M, Jayatissa A H. Ammonia gas sensing behavior of graphene surface decorated with gold nanoparticles. Solid State Electron, 2012, 78: 159-165

68 Esfandiar A, Ghasemi S, Irajizad A, et al. The decoration of $\mathrm{TiO}_{2} /$ reduced graphene oxide by $\mathrm{Pd}$ and $\mathrm{Pt}$ nanoparticles for hydrogen gas sensing. Int J Hydrogen Energ, 2012, 37: 15423-15432

69 Mao S, Cui S M, Lu G H, et al. Tuning gas-sensing properties of reduced graphene oxide using tin oxide nanocrystals. J Mater Chem, 2012, 22: 11009-11013

70 Singh G, Choudhary A, Haranath $\mathrm{D}$, et al. ZnO decorated luminescent graphene as a potential gas sensor at room temperature. Carbon, 2012, 50: 385-394

71 Zhou L S, Shen F P, Tian X K, et al. Stable $\mathrm{Cu}_{2} \mathrm{O}$ nanocrystals grown on functionalized graphene sheets and room temperature $\mathrm{H}_{2} \mathrm{~S}$ gas sensing with ultrahigh sensitivity. Nanoscale, 2013, 5: 1564-1569

72 Deng S Z, Tjoa V, Fan H M, et al. Reduced graphene oxide conjugated $\mathrm{Cu}_{2} \mathrm{O}$ nanowire mesocrystals for high-performance $\mathrm{NO}_{2}$ gas sensor. J Am Chem Soc, 2012, 134: 4905-4917

73 An X Q, Yu J C, Wang Y, et al. $\mathrm{WO}_{3}$ nanorods/graphene nanocomposites for high-efficiency visible-light-driven photocatalysis and $\mathrm{NO}_{2}$ gas sensing. J Mater Chem, 2012, 22: 8525-8531

74 Huang X H, Hu N T, Gao R G, et al. Reduced graphene oxide-polyaniline hybrid: Preparation, characterization and its applications for ammonia gas sensing. J Mater Chem, 2012, 22: 22488-22495

75 Jang W K, Yun J, Kim H I, et al. Improvement of ammonia sensing properties of polypyrrole by nanocomposite with graphitic materials. Colloid Polym Sci, 2012, doi: 10.1007/s00396-012-2832-6
76 Fu X L, Lou T T, Chen Z P, et al. "Turn-on" fluorescence detection of lead ions based on accelerated leaching of gold nanoparticles on the surface of graphene. ACS Appl Mater Interface, 2012, 4: 10801086

77 Li M, Zhou X J, Guo S W, et al. Detection of lead (II) with a "Turn-On" fluorescent biosensor based on energy transfer from $\mathrm{CdSe} / \mathrm{ZnS}$ quantum dots to graphene oxide. Biosens Bioelectron, 2013, 43: 49-74

78 Liu L, Liu W T, hong $\mathrm{T} \mathrm{T}$, et al. $\mathrm{Ag}^{+}$and cysteine detection by $\mathrm{Ag}^{+}-$ guanine interaction based on grapheme oxide and G-quadruplex DNA. Anal Method, 2012, 4: 1935-1939

79 Wen Y Q, Xing F F, He S J, et al. A graphene-based fluorescent nanoprobe for silver(I) ions detection by using graphene oxide and a silver-specific oligonucleotide. Chem Commun, 2010, 46: 25962598

80 Wen Y Q, Peng C, Li D, et al. Metal ion-modulated grapheneDNAzyme interactions: Design of a nanoprobe for fluorescent detection of lead(II) ions with high sensitivity, selectivity and tunable dynamic range. Chem Commun, 2011, 47: 6278-6280

81 Zhang M, Yin B C, Tan W H, et al. A versatile graphene-based fluorescence "on/off" switch for multiplex detection of various targets. Biosens Bioelectron, 2011, 26: 3260-3265

82 Zhang J R, Huang W T, Xie W Y, et al. Highly sensitive, selective, and rapid fluorescence $\mathrm{Hg}^{2+}$ sensor based on DNA duplexes of poly(dT) and graphene oxide. Analyst, 2012, 137: 3300-3305

83 Sudibya $\mathrm{H} \mathrm{G}, \mathrm{He}$ Q, Zhang $\mathrm{H}$, et al. Electrical detection of metal ions using field-effect transistors based on micropatterned reduced grapheme oxide films. ACS Nano, 2011, 5: 1990-1994

84 Chen K H, Lu G H, Chang J B, et al. Hg(II) ion detection using thermally reduced graphene oxide decorated with functionalized gold nanoparticles. Anal Chem, 2012, 84: 4057-4062

85 Zhao Z Q, Chen X, Yang Q, et al. Selective adsorption toward toxic metal ions results in selective response: Electrochemical studies on a polypyrrole/reduced graphene oxide nanocomposite. Chem Commun, 2012, 48: 2180-2182

86 Zhou H, Wang X, Yu P, et al. Sensitive and selective voltammetric measurement of $\mathrm{Hg}^{2+}$ by rational covalent functionalization of graphene oxide with cysteamine. Analyst, 2012, 137: 305-308

87 Wei Y, Gao C, Meng F L, et al. $\mathrm{SnO}_{2} /$ reduced graphene oxide nanocomposite for the simultaneous electrochemical detection of cadmium(II), lead(II), copper(II), and mercury(II): An interesting favorable mutual interference. J Phy Chem C, 2012, 116: 1034-1041

88 Gao C, Yu X Y, Xu R X, et al. AlOOH-reduced graphene oxide nanocomposites: one-pot hydrothermal synthesis and their enhanced electrochemical activity for heavy metal ions. ACS Appl Mater Interfaces, 2012, 4: 4672-4682

89 Ion I, Ion A C. Differential pulse voltammetric analysis of lead in vegetables using a surface amino-functionalized exfoliated graphite nanoplatelet chemically modified electrode. Sensor Actuat B: Chem, 2012, 166-167, 842-847

90 Li S J, Qian C, Wang K, et al. Application of thermally reduced grapheme oxide modified electrode in simultaneous determination of dihydroxybenzene isomers. Sensor Actuat B: Chem, 2012, 174: 441-448

$91 \mathrm{Xu} \mathrm{C} \mathrm{H}$, Wang J C, Wan L, et al. Microwave-assisted covalent modification of graphene nanosheets with hydroxypropyl- $\beta$ cyclodextrin and its electrochemical detection of phenolic organic pollutants. J Mater Chem, 2011, 21: 10463

92 Liu Z N, Ma X M, Zhang H C, et al. Simultaneous determination of nitrophenol isomers based on $\beta$-cyclodextrin functionalized reduced graphene oxide. Electroanal, 2012, 24: 1178-1185

93 Zhu G B, Gai P B, Wu L, et al. $\beta$-cyclodextrin-platinum nanoparticles/graphene nanohybrids: Enhanced sensitivity for electrochemical detection of naphthol isomers. Chem Asian J, 2012, 7: 732-737

94 Zhang Y, Zhang J L, Wu H X, et al. Glass carbon electrode modified with horseradish peroxidase immobilized on partially reduced graphene oxide for detecting phenolic compounds. J Electroanal Chem, 2012, 681: 49-55 
$95 \mathrm{Xu}$ Q, Li X J, Zhou Y E, et al. An enzymatic amplified system for the detection of 2,4-dichlorophenol based on graphene membrane modified electrode. Anal Method, 2012, 4: 3429-3435

96 Wu L D, Deng D H, Jin J, et al. Nanographene-based tyrosinase biosensor for rapid detection of bisphenol A. Biosens Bioelectron, 2012, 35: 193-199

97 Zhao Y C, Song X Y, Song Q S, et al. A facile route to the synthesis copper oxide/reduced graphene oxide nanocomposites and electrochemical detection of catechol organic pollutant. Crystengcomm, 2012, 14: 6710-6719

98 Si W M, Lei W, Zhang Y H, et al. Electrodeposition of graphene oxide doped poly(3,4-ethylenedioxythiophene) film and its electrochemical sensing of catechol and hydroquinone. Electrochim Acta, 2012, 85: 295-301

99 Zheng L Z, Xiong L Y, Li Y D, et al. Facile preparation of polydopamine-reduced graphene oxide nanocomposite and its electrochemical application in simultaneous determination of hydroquinone and catechol. Sensor Actuat B: Chem, 2013, 177: 344-349

100 Wang Y, Zhang S, Du D, et al. Self assembly of acetylcholinesterase on a gold nanoparticles-graphene nanosheet hybrid for organophosphate pesticide detection using polyelectrolyte as a linker. J Mater
Chem, 2011, 21: 5319-5325

101 Zhang L, Zhang A D, Du D, et al. Biosensor based on prussian blue nanocubes/reduced graphene oxide nanocomposite for detection of organophosphorus pesticides. Nanoscale, 2012, 4: 4674-4679

102 Gong J M, Miao X J, Wan H F, et al. Facile synthesis of zirconia nanoparticles-decorated graphene hybrid nanosheets for an enzymeless methyl parathion sensor. Sensors Actuat B: Chem, 2012, 162: 341347

103 Liang H, Miao X J, Gong J M, et al. One-step fabrication of layered double hydroxides/graphene hybrid as solid-phase extraction for stripping voltammetric detection of methyl parathion. Electrochem Commun, 2012, 20: 149-152

104 Zhang K, Song G, Yang L X, et al. A novel self-assembly voltammetric sensor for malachite green based on ethylenediamine and graphene oxide. Anal Method, 2012, 4: 4257-4263

105 Huang S T, Shi Y, Li N B, et al. Fast and sensitive dye-sensor based on fluorescein/reduced graphene oxide Complex. Analyst, 2012, 137: 2593-2599

106 Wang T, Zhu Y, Li G, et al. A novel hydrogen peroxide biosensor based on the BPT/AuNPs/graphene/HRP composite. Sci China Chem, 2011, 54: 1645-1650

Open Access This article is distributed under the terms of the Creative Commons Attribution License which permits any use, distribution, and reproduction in any medium, provided the original author(s) and source are credited. 